\title{
The Structural Proteins of Bdellovibrio bacteriovorus Bacteriophage MAC-1
}

\author{
Rajinder S. Ranu',2, Renee Gallegos², Mary Althauser ${ }^{2}$, Lisa Wolfe ${ }^{3}$ \\ ${ }^{1}$ Laboratory of Plant Molecular Biology \& Biotechnology, Department of Bioagricultural Sciences \& Pest \\ Management, Colorado State University, Fort Collins, CO, USA \\ ${ }^{2}$ Department of Microbiology, Colorado State University, Fort Collins, CO, USA \\ ${ }^{3}$ Proteomics \& Metabolomics Facility, Colorado State University, Fort Collins, CO, USA \\ Email: rranu@colostate.edu
}

Received 30 May 2016; accepted 27 August 2016; published 30 August 2016

\begin{abstract}
In the present investigation the structural proteins associated with MAC-1 bacteriophage have been characterized using sodium dodecyl sulfate-polyacrylamide gel electrophoresis (SDS-PAGE); tandem mass spectrometry of protein bands from SDS-PAGE gel; from the open reading frames (ORFs) deduced from MAC-1 genome sequence and amino acid sequence homology searches from the Uniprot database (up000002418). Results have led to the identification of at least three structural proteins associated with MAC-1 phage genome. They are: capsid protein $(\sim 55,000$-daltons); spike protein $(\sim 22,000$-daltons $)$ and a low molecular weight DNA binding protein $(\sim 4000$-daltons). In addition, two other minor proteins were tentatively identified as replicative and scaffold proteins based on two to three unique peptides from mass spectrometry data. However, other proteins coded (ORFs) by phage genome remain to be identified.
\end{abstract}

\section{Keywords}

Bdellovibrio bacteriovorus Bacteriophage, MAC-1 Phage Structural Proteins, MAC-1 Genome, MAC-1 Genes (ORFs)

\section{Introduction}

Bdellovibrio bacteriovorus are extremely small, highly motile gram negative soil-inhibiting bacteria that parasitize and replicate in other gram negative bacteria [1]-[4]. They are also found in aquatic and normal plant material. They are the smallest predators known ([1]-[4]; reviewed in [4] and [5]). They exhibit two different life styles: a free living phase and a growth phase that is spent in the prey cell. The highly motile Bdellovibrios attacks a susceptible host, and gets attached to it. By creating a hole through the cell wall, it gains entrance into the periplasmic space of the prey cell and the host macromolecular synthesis is immediately shut down. The host is killed. The Bdellovibrio elaborates a series of degradative enzymes [5] resulting in efficient degradation of host macromolecules that are then utilized to synthesize the progeny Bdellovibrios in the form of a long filament. This filament undergoes fragmentation into unit length Bdellovibrio cells concomitant with the synthesis of a flagellum. The progeny cell is released upon lysis of the empty prey shell. In nature only the parasitic form (also 
called host-dependent form) of Bdellovibrio is observed [2] [4]. Host independent mutants devoid of parasitic activity and capable of growing on artificial medium have been described [2] [5] and have been widely used to study these organisms (reviewed in [4]). Recently the entire genome of B. bacteriovorus has been sequenced [5]. In addition to many genes that appear to be unique to Bdellovibrio, a notable feature in the genome is the presence of multiple genes that are adopted to the life style of these organisms. This includes a suite of genes that code for a variety of degradative enzymes for efficient breakdown of prey cell macromolecules which are used for its own replication [1]-[5]. They represent an ultimate case of parasitism, and there is almost nothing left of the prey cell; because of this fact, there is considerable interest for their use as biological control agents against gram negative pathogenic bacteria in plant and animal systems [6] [7].

A group of bacteriophages that specifically infect B. bacteriovorus species have been described [8]-[11]; they are sometimes called bdellophages [8]-[10]. Some of these phages are able to attack host independent strains whereas others can only grow in host-dependent strains [8]-[11]. In our previous studies we described molecular characteristics of one of the isometric bacteriophages called MAC-1 [12] and showed that phage genome was circular single stranded DNA that replicated via a double stranded intermediate [12]-[14]. These results suggested that MAC-1 was a unique phage that was considerably smaller to $\Phi$ X174 genome [12].

In the present communication the structural proteins of MAC-1 bacteriophage have characterized using sodium dodecyl sulfate-polyacrylamide gel electrophoresis (SDS-PAGE); mass spectrometry; from the open reading frames (ORFs) deduced from MAC-1 genome sequence and amino acid sequence homology searches from the Uniprot database (up000002418). Results have led to identification of at least three structural proteins associated with MAC-1 phage genome.

\section{Materials \& Methods}

\subsection{Bacterium and Bacteriophage}

A host independent strain of B. bacteriovorus (ATCC 25631) obtained from American Type Culture Collection was grown on culture medium containing peptone $(1 \%)$ and yeast extract $(0.3 \%)$. All incubations were at $30^{\circ}$. Liquid cultures were grown on a shaker. The MAC-1 phage titer was determined according to Adams [15] and high titer phage was prepared according to Hershey et al. [16] except that large petri plates $(150 \times 15 \mathrm{~mm})$ were used. The original MAC-1 bacteriophage was provided by Dr. Mary Althauser [10].

\subsection{Other Materials}

Restriction enzymes, T4 DNA ligase and other nucleic acid enzymes used for DNA manipulation were from US Biological or New England Biolabs. DNA sequencing kits based either on Sequenase or Themo Sequenase were from Amersham/Pharmacia Biochemical. Sources other materials have been described [12] [17]-[20].

\subsection{Preparation of MAC-1 DNA}

Bacteriophage from high titer broth culture was precipitated with $2.5 \% \mathrm{NaCl}$ and $10 \%$ polyethylene glycol. The precipitate was collected and dissolved in buffered saline [20 mM potassium phosphate (pH 6.8), $150 \mathrm{mM} \mathrm{NaCl}$ and $5 \mathrm{mM} \mathrm{Mg}$ acetate]. It was further purified by two consecutive cycles of isopycnic density gradient centrifugation in $\mathrm{CsCl}$ (beginning with density of $1.36 \mathrm{~g} / \mathrm{ml}$ ); the phage stock (with a titer of $6 \times 10^{14}$ to $1 \times 10^{15} / \mathrm{ml}$ ) was used to isolate phage nucleic acid according to Maniatis et al. [18].

\subsection{DNA Sequencing}

The sequence of phage genome was determined by using two step sequence system with $\left[{ }^{35} \mathrm{~S}\right] \mathrm{dATP}$ using Sequenase or deltaTaq DNA polymerase [18] [21] [22]. In our latter sequencing work we used $\left.{ }^{32} \mathrm{P}\right]$ labeled terminators and Thermo Sequenase [23] because in this system only properly terminated chains are labeled and visualized in an autoradiograph of a sequencing gel. The band intensities are remarkably uniform. Moreover, PCR based cycle sequencing requires very small amounts of the template DNA. There are very few, if any, artifacts generated in DNA sequence due to high secondary structures in DN template. Experimental details of the method have been described [23]. Final DNA sequence of phage genome was developed by sequencing both the strands. 


\subsection{Analyses of MAC-1 Bacteriophage Proteins}

Phage purified by two consecutive isopycnic density gradient centrifugations in $\mathrm{CsCl}$ was dialyzed against phosphate buffered saline to remove CsCl. Phage stock $\left(5 \times 10^{14}\right.$ to $\left.1 \times 10^{15}\right)$ was used to analyze phage proteins. For this purpose an aliquot of phage was treated with denaturing solution containing $[0.1 \mathrm{mM}$ Tris- $\mathrm{HCl}(\mathrm{pH} 7.0)$; $5 \% \beta$-Mercaptoethanol; $10 \%$ Sodium Dodecyl Sulfate and $10 \%$ glycerol] and sample was heated at $95^{\circ} \mathrm{C}$ for 5 minutes to allow complete denaturation of phage protein and their dissociation from phage DNA. An aliquot of the sample was applied to SDS-polyacrylamide (11\% - 12\%) gel [24] and standard proteins were used as molecular weight markers in a separate lane. They were subjected to electrophoresis to resolve the proteins. Western blot of resolved proteins in SDS-polyacrylamide gel was performed as described before [17] except that $\left[{ }^{125} \mathrm{I}\right]$ labeled protein A was used for protein detection by autoradiography.

\subsection{Preparation of Antibodies against Bacteriophage Proteins}

Antibodies against the purified whole phage were prepared in rabbits using the standard immunization protocol [17] [18]. The antibodies against individual phage proteins resolved by SDS-gel electrophoresis were also raised. For this purpose individual stained protein band from SDS-gel were cut out, homogenized in tight fitting homogenizer and then injected in a rabbit. Final immunization results showed that both the neutralizing antibodies [15] and antibodies against individual proteins were elicited by immunization with the whole phage and individual proteins. Details of other procedures used in our studies have been described [17]-[21] [23].

\subsection{LC-MS/MS Analysis: In-Gel Trypsin Digestion}

Sample bands of interest from dried SDS-PAGE gel were scored and cut out with a razor blade and then were completely cut from the paper (See Figure 1 below). After rehydration in LC-MS grade water, the gel fragments were then subjected to in-gel trypsin digestion for LC-MS/MS as previously described [25]. Briefly, the gel pieces were washed with $200 \mu \mathrm{L}$ of LC-MS Grade Water (Optima LC-MS, Fisher Scientific) for $30 \mathrm{~s}$ and destained with $2 \times 200 \mu \mathrm{L}$ of $50 \%$ Acetonitrile (ACN; Optima LC-MS Grade) $/ 50 \mathrm{mM}$ Ammonium bicarbonate at $60^{\circ} \mathrm{C}$, with intermittent mixing. The pieces were dehydrated with $100 \% \mathrm{ACN}$ and allowed to air dry. Proteins were reduced and alkylated, in-gel with $25 \mathrm{mM}$ DTT in $50 \mathrm{mM}$ Ammonium bicarbonate $\left(60^{\circ} \mathrm{C}\right.$ for $\left.20 \mathrm{~min}\right)$ and $55 \mathrm{mM}$ IAA in $50 \mathrm{mM}$ Ammonium bicarbonate at room temperature in the dark for $20 \mathrm{~min}$. Gel pieces were then washed with Optima water and dried. The dried gel pieces were rehydrated in $20 \mu \mathrm{L} 12 \mathrm{ng} / \mu \mathrm{L}$ MS-grade Trypsin (ThermoPierce, San Jose, CA) /0.01\% ProteaseMAX surfactant/50 mM ammonium bicarbonate mixture for $10 \mathrm{~min}$ at room temperature, overlaid with $30 \mu \mathrm{L} 0.01 \%$ ProteaseMAX surfactant $/ 50 \mathrm{mM}$ ammonium bicarbonate and incubated at $50^{\circ} \mathrm{C}$ for $1 \mathrm{~h}$. Extracted peptides were transferred and the digestion halted by addition of $10 \%$ trifluoro-acetic acid to a final concentration of $0.5 \%$. Peptide extracts were dehydrated and stored at $-20^{\circ} \mathrm{C}$ prior to analysis by LC-MS/MS.

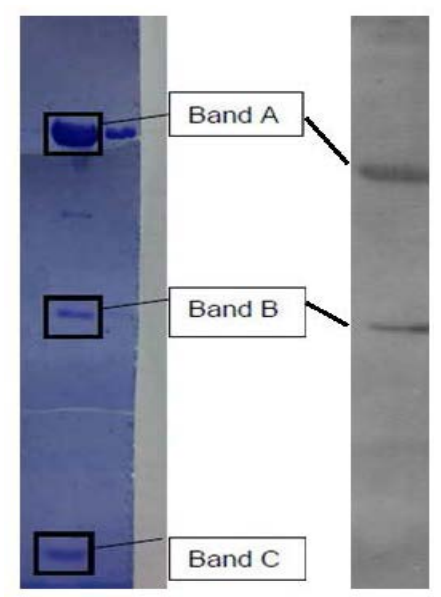

Figure 1. Coomassie brilliant blue trained SDS-PAGE of proteins extracted from purified MAC-1 phage (left) and an autoradiograph of a Western blot (right). Minor protein band between band A and B is a proteolytic digestion product of band A. 


\subsection{Mass Spectrometry Analysis}

Peptides were purified and concentrated using an on-line enrichment column (Thermo Scientific $5 \mu \mathrm{m}, 100 \mu \mathrm{m}$ ID $\times 2 \mathrm{~cm}$ C18 column). Subsequent chromatographic separation was performed on a reverse phase nanospray column (Thermo Scientific EASYnano-LC, $3 \mu \mathrm{m}, 75 \mu \mathrm{m}$ ID $\times 100 \mathrm{~mm}$ C18 column) using a 30 minute linear gradient from $10 \%$ - 30\% buffer B (100\% ACN, 0.1\% formic acid) at a flow rate of 400 nanoliters $/ \mathrm{min}$. Peptides were eluted directly into the mass spectrometer (Thermo Scientific Orbitrap Velos) and spectra were collected over a m/z range of 400 - 2000 Da using a dynamic exclusion limit of 2 MS/MS spectra of a given peptide mass for $30 \mathrm{~s}$ (exclusion duration of $90 \mathrm{~s}$ ). The instrument was operated in Orbitrap-LTQ mode where precursor measurements were acquired in the orbitrap (60,000 resolution) and MS/MS spectra (top 20) were acquired in the LTQ ion trap with a normalized collision energy of $35 \mathrm{kV}$. Compound lists of the resulting spectra were generated using Xcalibur 2.2 software (Thermo Scientific) with a S/N threshold of 1.5 and 1 scan/group.

\subsection{Data Analysis}

Tandem mass spectra were extracted, charge state deconvoluted and deisotoped by ProteoWizard MsConvert (version 3.0). All MS/MS samples were analyzed using Mascot (Matrix Science, London, UK; version 2.3.01). Mascot was set up to search the MAC-1 data generated in all possible open reading frames (ORFs) from the genome sequence and the Uniprot databases assuming the digestion enzyme trypsin. Mascot was searched with a fragment ion mass tolerance of $0.80 \mathrm{Da}$ and a parent ion tolerance of 20 PPM. Oxidation of methionine, carboxymethylation of cysteine, was specified in Mascot as variable modifications.

Search results from all samples were imported and combined using the probabilistic protein identification algorithms 1 implemented in the Scaffold software (version Scaffold_4.4.1.1, Proteome Software Inc., Portland, OR). Peptide identifications were accepted if they could be established at greater than $50.0 \%$ probability by the Peptide Prophet algorithm of Keller et al. [26] with Scaffold delta-mass correction. Protein identifications were accepted if they could be established at greater than 90\% probability and contained at least 2 identified peptides. Protein probabilities were assigned by the Protein Prophet algorithm (Nesvizhskii et al. [26]-[29]). Proteins that contained similar peptides and could not be differentiated based on MS/MS analysis alone were grouped to satisfy the principles of parsimony.

\subsection{Quality Control}

Instrument functionality and stability was monitored using the MassQC software (Proteome Software). This software uses a set of quantitative metrics developed by the National Institute of Science and Technology (NIST) in collaboration with the National Cancer Institute's Clinical Proteomic Technologies for Cancer (CPTC) that monitor technical variability in mass spectrometry-based proteomics instrumentation 5. Quality control samples containing a mixture of 6 trypsin digested bovine proteins were injected at least once every 24 hours throughout the analysis, and the data from this run was analyzed using the MassQC software. Values for all metrics were within normal limits throughout the duration of the experiment indicating instrument stability and data robustness.

\section{Results and Discussion}

In this communication we focus primarily on the proteins associated with the MAC-1 phage particle, which we call as the structural proteins. For the purposes of an overview, however, we have included the physical properties of MAC-1 phage particle as well as its genome. They are listed in Table 1. For comparison, physical properties of $\Phi$ X174 phage and the prototype of ssDNA phages are also included [30]. Although we have complete sequence of MAC-1 genome, it will not be the focus in this report, only to the extent that information derived from the all possible six ORFs is being used to verify and identify genes coding for the structural proteins.

The structural proteins associated with the purified MAC-1 phage were resolved by SDS-PAGE electrophoresis. A representative of the data is presented in Figure 1. Three polypeptides can be readily observed, listed as A ( 55,000-daltons), B ( 22,000-daltons), and C ( 4000-daltons). Antibodies prepared against the whole phage exhibited two properties. An early antiserum harvested after 10 days of immunization showed high phage neutralizing titer (results not shown) but failed to react with any of the protein bands in Western blots. However, antiserum harvested in later stages of immunization reacted with two protein bands, which were identified as protein bands A and B in Figure 1 (right panel). 
To further identify the nature of proteins in these various SDS-PAGE protein bands, we determined the amino acid sequence by LC/MS/MS spectrometry. Briefly, the protein band was cut out, digested with trypsin and resolved peptides were subjected to tandem mass spectrometry. Details were described in Materials \& Methods. The MS/MS spectra were used to determine sequence homology against all possible six ORFs of the MAC-1 genome and the Uniprot database (up000002418). For the purposes of completeness, we also took additional protein bands from overloaded SDS-PAGE gel in the hope that we may be able to find minor structural protein(s) that are not otherwise visible in the gel. Data from these various analyses and amino acid homologies are shown in Figure 2. From this data we conclude that protein band A is the major capsid or coat protein (VP1); band B is spike protein and band C is DNA binding protein.

Based on two to three spectra from the protein bands cut out from the over-loaded SDS-PAGE gel, we were able to tentatively identify two additional, minor proteins as the replicative and scaffold proteins (results not shown). Most of the other protein bands were proteolytic digestion products bands A and B.

Figure 3 shows electron micrographs of MAC-1 phage, except for better details, these results closely resemble EM of MAC-1 originally published by Althauser et al. [10]. The new EM picture shows an additional fea-

\section{Capsid Protein (VP1) - 76\% Sequence Coverage}

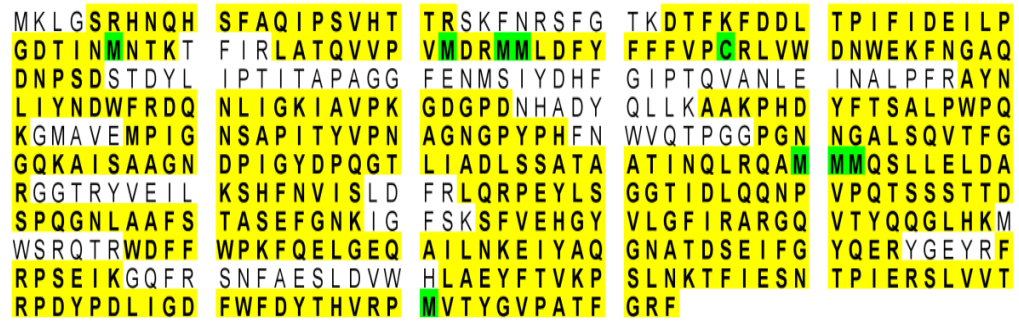

Spike Protein - 72\% Sequence Coverage

\section{Band A}


Table 1. Physical Properties of MAC-1 compared with ФX174.

\begin{tabular}{ccc}
\hline Phage & MAC-1 & $\Phi$ X174 \\
Size & $20+\mathrm{nm}$ & $25 \mathrm{~nm}$ \\
Density & 1.373 & 1.4 \\
S $_{20 \mathrm{w}}$ & $94 \mathrm{~S}$ & $114 \mathrm{~S}$ \\
DNA & $17.9 \mathrm{~S}$ & $24 \mathrm{~S}$ \\
Mol. Wt. & $1.57 \times 10^{6}$ & $1.77 \times 10^{6}$ \\
Genome & $4590+\mathrm{nt}$ & $5386 \mathrm{nt}$ \\
\hline
\end{tabular}

Both are an icosahedron with a circular single stranded genome.

ture which is consistent with the presence of spikes (Figure 3; EM on right). Our phage neutralization data with early antibodies, coupled with the MS/MS results; the homology data from MAC-1 genome ORFs and Uniprot database also support the presence of spike protein. We are faced with an anomaly, the EM of phage ФMH2K by Brentlinger et al. [31] has no resemblance with our recent EM or that of Athauser et al. [10]. Moreover, these authors state that $\Phi \mathrm{MH} 2 \mathrm{~K}$ does not contain spike protein. Our results, on the other hand, are consistent with the presence of spike protein (Figure 2 and Figure 3). However, when the genome sequence of MAC-1 is compared with $\Phi \mathrm{MH} 2 \mathrm{~K}$ genome, they are almost identical including the ORFs. How could genome sequence of $\Phi M H 2 \mathrm{~K}$ be identical to MAC-1 but the EM morphology be completely different? This is a complete contradiction. What is the source of the sequence? It cannot be $\Phi \mathrm{MH} 2 \mathrm{~K}$ which morphologically has no resemblance to MAC-1 phage. In their paper the authors also state no data on the genome of MAC-1 is available. This is not the case. All the data were available, if only, the authors had looked into the databases including a review [12]-[14]. Pretentiousness of their originality of the phage isolation from the raw sewage does not withstanding, we believe real source of this phage is Richard C. Roberts who worked in the senior author's laboratory (Ranu) whose tenure at the University of California, San Diego overlapped with one of the authors in this paper on ФМH2K phage [31].

Finally, based on the sequence of MAC-1, size of genome, the lack of DNA sequence homology with ФX174 phage genome [2]-[14] and the data from analyses of the structural proteins, we believe MAC-1 represents a unique phage with the smallest genome yet. The assignment of other ORFs to phage expressed proteins will have to wait further investigations.

\section{Acknowledgements}

This work is supported by an NIH BRSG research grant. Expert technical assistance of Kitty Brown on Mass Spectrometry experiments is gratefully acknowledged.

\section{References}

[1] Stolp, H. and Starr, M.P. (1963) Bdellovibrio bacteriovorus gen. et sp. n., a Predatory, Ectoparasitic and Bacteriolytic Microorganism. Antonie van Leeuwenhoek J. Microbiol, 99, 217-248. http://dx.doi.org/10.1007/BF02046064

[2] Seidler, R.J. and Starr, M.P. (1969) Isolation and Characterization of Host-Independent Bdellovibrios. J. Bacteriol, 100, 769-785.

[3] Rittenberg, S.C. (1983) Bdellovibrio: Attack, Penetration and Growth on Its Prey. American Society of Microbiology News, 49, 435-439.

[4] Ruby, E.D. (1992) The Genus Bdellovibrio. In: Balows, A., Triiper, H.G., Dworkin, M., Harder, W. and HeinzSchleifer, K., Eds., The Prokaryotes, Volume IV, Springer, New York, 3400-3415. http://dx.doi.org/10.1007/978-1-4757-2191-1_25

[5] Rendulic, S., Jagtap, P., Rosinus, A., Eppinger, M., Baar, C., Lanz, C., Keller, H., Lambert, C., Evans, K.J., Goesmann, A., Meyer, F., Sockett, R.E. and Schuster, S.C. (2004) A Predator Unmasked: Life Cycle of Bdellovibrio bacteriovorus from a Genome Perspective. Science, 303, 689-692. http://dx.doi.org/10.1126/science.1093027

[6] Harini, K., Ajila, V. and Hegde, S. (2013) Bdellovibrio bacteriovorus: A Future Antimic, Vrobial Agent? J Indian Soc Periodonto, 17, 823-825. http://dx.doi.org/10.4103/0972-124X.124534 
[7] Olanya, O.M. and Lakshman, D.K. (2015) Potential of Predatory Bacteria as Biocontrol Agents for Foodbourne and Plant Pathens. J. Plant Pathology, 97, 405-417

[8] Diedrich, D.L., Denny, C.F., Hashimoto, T. and Conti, S.F. (1970) Facultatively Parasitic Strain of Bdellovibrio bacteriovorus. J. Bacteriol, 101, 989-996.

[9] Hashimoto, T., Diedrich, D.L. and Conti, S.F. (1970) Isolation of Bacteriophage for Bdellovibrio bacteriovorus. J. Virol, 5, 97-98.

[10] Althauser, M., Samsonoff, W.A., Anderson, C. and Canti, S.F. (1972) Isolation and Preliminary Characterization of Bacteriophages of Bdellovibrio bacteriovorus. J. Virol, 10, 516-523.

[11] Varon, M. and Levisohn, R. (1972) Three-Membered Parasitic System: A Bacteriophage, Bdellovibrio bacteriovorus, and Escherichia coli. J. Virol, 9, 519-525.

[12] Roberts, R.C., Keefer, M.A. and Ranu, R.S. (1987) Characterization of Bdellovibrio bacteriovorus Bacteriophage MAC- 1. J.Gen. Microbiol, 133, 3065-3070. http://dx.doi.org/10.1099/00221287-133-11-3065

[13] Roberts, R.C. and Ranu, R.S. (1987) Transfection of Bdellovibrio bacteriovorus with bacteriophage MAC-1 DNA. FEMS Microbiol let, 43, 207-211. http://dx.doi.org/10.1111/j.1574-6968.1987.tb02124.x

[14] Ranu, R.S. (2002) Natural Single Stranded DNA. In: Encyclopedia of life Sciences, John Wiley \& Sons, 1-8.

[15] Adams, M. (1959) Bacteriophages. Wiley Interscience, New York.

[16] Hershey, A.D., Kalmansogn, D. and Bronfenbrenner, J. (1943) Quantitative Methods in the Study of the Phage-Antiserum Reaction. Journal of Immunology, 46, 267-280.

[17] Ranu, R.S., Gowda, S., Scholthof, H., Wu, F.G. and Shepherd, R.J. (1996) In Vitro Translation of the Full-Length RNA Transcript of Figwort Mosaic Virus (Caulimovirus). Gene Expr, 5, 143-145.

[18] Maniatis, T., Fritsch E.F. and Sambrook, J.K. (1982) Molecular Cloning: A Laboratory Manual. Cold Spring Harbor Laboratory, Cold Spring Harbor.

[19] Roberts, R.C. (1987) Characterization of Bdellovibrio bacteriovorus Bacteriophage MAC-1. M.S. Thesis, Submitted to Colorado State University, Fort Collins.

[20] Gallegos, R. (1988) Studies on the Genome of Bacteriophage MAC-1. M. S. Thesis, Submitted to Colorado State University, Fort Collins

[21] Ranu, R.S. (1995) DNA Sequencing by delta-Taq DNA Polymerase. BioTechniques, 18, 390-393.

[22] Sanger, F., Milklen, S. and Coulson, A.R. (1977) DNA Sequencing with Chain-Terminating Inhibitors. Proc. Natl. Acad. Sci. USA, 74, 5463-5467. http://dx.doi.org/10.1073/pnas.74.12.5463

[23] Fan, J., Ranu, R.S., Smith, C., Ruan, C. and Fuller, C.W. (1996) DNA Sequencing with [Alpha- ${ }^{33}$ P]-Labeled ddNTP Terminators: A New Approach to DNA Sequencing with ThermoSequenase ${ }^{\mathrm{TM}}$ DNA Polymerase. BioTechniques, 21, 1132-1137.

[24] Laemmeli, U.K. (1970) Cleavage of Structural Proteins during the Assembly of the Head of Bacteriophage T4. Nature (London), 227, 680-685. http://dx.doi.org/10.1038/227680a0

[25] Saveliev, S.V., Woodroofe, C.C., Sabat, G., Adams, C.M. and Klaubert, D. (2013) Mass Spectrometry Compatible Surfactant for Optimized In-Gel Protein Digestion. Anal. Chem, 907-914.

[26] Keller, A., Nesvizhskii, A.I., Kolker, E. and Aebersold, R. (2002) Empirical Statistical Model to Estimate the Accuracy of Peptide Identifications Made by MS/MS and Database Search. Analytical Chemistry, 74, 5383-5392. http://dx.doi.org/10.1021/ac025747h

[27] Searle, B.C., Tuner, M. and Nesvizhskii, A.I. (2008) Improving Sensitivity by Probabilistically Combining Results from Multiple MS/MS Search Methodologies. J. Proteome Research, 7, 245-253. http://dx.doi.org/10.1021/pr070540w

[28] Kall, L., Storey, J.D., MacCoss, M.J. and Noble, W.S. (2008) Assigning Significance to Pepides Identified by Tandem Mass Spectrometry Using Decoy Database. J. Proteome Research, 7, 29-34. http://dx.doi.org/10.1021/pr700600n

[29] Nesvizhskii, A.I., Keller, E. and Aebersold, R. (2003) A Statistical Model for Identifying Proteins by Tandem Mass Spectrometry. Analytical Chemistry, 75, 4646-4658. http://dx.doi.org/10.1021/ac0341261

[30] Godson, G.N. (1978) The Isometric Phages. In: Denhardt, D.T., Dressler, D.and Ray, D.S., Eds., The Single Stranded DNA Phages, Cold Spring Harbor Laboratory, Cold Springer Harbor, 103-112.

[31] Brentlinger, K.L., Hafenstein, S., Novak, C.R., Fane, B.A., Borgon, R., McKenna, R. and Agbandje-McKenna, M. (2002) Microviridae, a Family Divided: Isolation, Characterization, and Genome Sequence of phiMH2K, a Bacteriophage of the Obligate Intracellular Parasitic Bacterium Bdelloovibrio bacteriovorus. J. Bacteriology, 184, 1089-1094. http://dx.doi.org/10.1128/jb.184.4.1089-1094.2002 


\section{Submit or recommend next manuscript to SCIRP and we will provide best service for you:}

Accepting pre-submission inquiries through Email, Facebook, LinkedIn, Twitter, etc.

A wide selection of journals (inclusive of 9 subjects, more than 200 journals)

Providing 24-hour high-quality service

User-friendly online submission system

Fair and swift peer-review system

Efficient typesetting and proofreading procedure

Display of the result of downloads and visits, as well as the number of cited articles

Maximum dissemination of your research work

Submit your manuscript at: http://papersubmission.scirp.org/ 